УДК 503.36

\title{
ОПТИМИЗАЦИЯ ПРОЦЕССА ПОЛУЧЕНИЯ НЕФТЯНЫХ СОРБЕНТОВ Из ОтХОДОВ ОКОРКИ ОсИнЫ
}

\author{
() Е.В. Веприкова", Е.А. Терещенко
} Институт химии и химической технологии СО РAH, Академгородок, 50/24,
Красноярск, 660036 (Россия), e-mail: veprikova2@mail.ru

Предложена двухфакторная математическая модель получения сорбентов из отходов окорки осины, предназначенных для очистки нефтяных загрязнений. Показано, что данная модель эффективно описывает зависимость нефтеемкости сорбентов от условий их получения - температуры процесса взрывного автогидролиза и давления водяного пара. На основании предложенной модели определены оптимальные условия получения сорбентов с максимальной нефтеемкостью.

Ключевые слова: окорка осины, взрывной автогидролиз, сорбент, нефтеемкость, математическая модель, оптимизация.

\section{Введение}

Удаление нефтяных загрязнений с поверхности воды и почвы является важной экологической задачей. Для решения этой задачи во всем мире широко используются сорбционные методы с применением различных нефтяных сорбентов. В последнее время перспективным направлением является получение нефтяных сорбентов из доступных и дешевых отходов, например, древесных [1]. Конкурентоспособность таких сорбентов определяется поглощением нефти и нефтепродуктов - нефтеемкостью. Величина нефтеемкости зависит от природы сырья и технологии получения сорбентов, поэтому задача оптимизации технологических условий имеет практический и научный интерес. Для практических целей поиска оптимальных условий получения сорбентов широко используются экспериментально-статистические методы, с помощью которых моделирование проводится при неизвестном механизме протекающих процессов с исследованием зависимости отклика системы на изменения входных параметров.

Цель работы - оптимизация условий получения нефтяных сорбентов из окорки осины методом взрывного автогидролиза, обеспечивающих максимальную сорбцию нефти и нефтепродуктов.

\section{Экспериментальная часть}

Сырьем для получения нефтяных сорбентов служили отходы окорки осины (содержание коры и древесины $1: 1)$. Сырье высушивали до воздушно-сухого состояния (8-10\%), а затем измельчали на дезинтеграторе марки «8255 Nossen» (Германия). Для получения сорбентов использовали фракцию окорки осины 0,5-1,5 мм.

Сорбенты из отходов окорки осины получали методом взрывного автогидролиза в среде водяного пара. Установка и способ получения нефтяных сорбентов подробно описаны в работе [2]. Нефтеемкость сорбентов (НЕ, г/г) определяли по сырой нефти Тюменского месторождения $\left(\rho-0,85\right.$ г/см $\left.{ }^{3}\right)$ при $20 \pm 2{ }^{\circ} \mathrm{C}$ по

Веприкова Евгения Владимировна - старший научный сотрудник, тел.: (391) 244-91-20, e-mail: veprikova2@mail.ru

Терещенко Елена Анатольевна - ведущий инженер, тел.: (391) 244-91-20, e-mail: tereshea@yandex.ru методике ТУ 214-10942238-03-95.

Математическое моделирование проводили с использованием статистических методов для получения полиномов, описывающих взаимосвязь результа-

\footnotetext{
* Автор, с которым следует вести переписку.
} 
тивного и факторных признаков. Результативным признаком является сорбционная емкость сорбента по нефти НЕ (г/г). Нефтеемкость представляет собой среднее значение по результатам трех определений. В качестве независимых факторных признаков были выбраны температура $\mathrm{T}\left({ }^{\circ} \mathrm{C}\right)$ процесса автогидролиза и давление пара Р (МПа). Методом регрессионного анализа определяли совместное влияние температуры Т и давления пара Р на нефтеемкость сорбента. Проверку значимости коэффициентов уравнений регрессии (уровень значимости $q=0,05$ ) и проверку эффективности регрессионной модели по критерию Фишера проводили в соответствии с правилами статистического анализа [3]. Для решения оптимизационной задачи использовали метод крутого восхождения по поверхности отклика [4].

\section{Результаты и обсуждение}

В результате предварительных экспериментов установлено влияние температуры и давления пара в процессе взрывного автогидролиза на нефтеемкость сорбентов из окорки осины (рис.1).

Данные, представленные на рисунке 1, позволяют выбрать границы варьирования выбранных факторов. Видно, что существенное увеличение нефтеемкости сорбентов достигается при давлении пара более 2,0 МПа. Повышение давления до 4,0 МПа приводит к снижению нефтеемкости сорбентов, полученных при температуре более $220{ }^{\circ} \mathrm{C}$. Таким образом, нижнюю и верхнюю границы варьирования давления пара при моделировании процесса получения сорбентов из окорки целесообразно принять равными 2,0 и 4,0 МПа, соответственно. Как следует из рисунка 1, нижняя и верхняя границы варьирования температуры автогидролиза должны выбираться не менее $170{ }^{\circ} \mathrm{C}$ и не более $260{ }^{\circ} \mathrm{C}$ соответственно.

При моделировании процесса получения сорбентов из окорки осины продолжительность взрывного автогидролиза составляет 60 с. Как показали предварительные эксперименты, такая продолжительность процесса обеспечивает самые высокие показатели нефтеемкости сорбентов (рис. 2).

Для получения математической модели процесса получения сорбентов из окорки осины использовали методы теории планирования эксперимента. Уровни варьирования факторов, необходимых для полного факторного эксперимента, представлены в таблице 1.

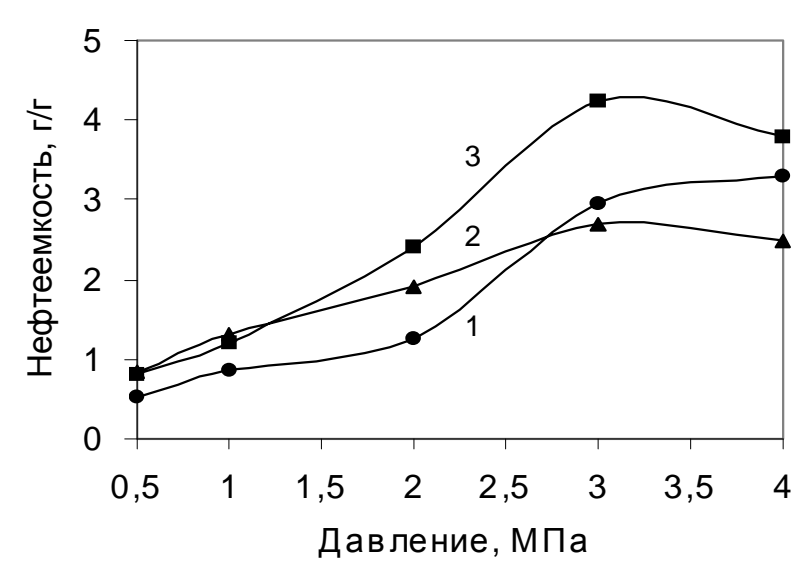

Рис. 1. Зависимость нефтеемкости сорбента из окорки осины от давления пара при разной температуре процесса взрывного автогидролиза: $1-170{ }^{\circ} \mathrm{C} ; 2-260{ }^{\circ} \mathrm{C} ; 3-220{ }^{\circ} \mathrm{C}$

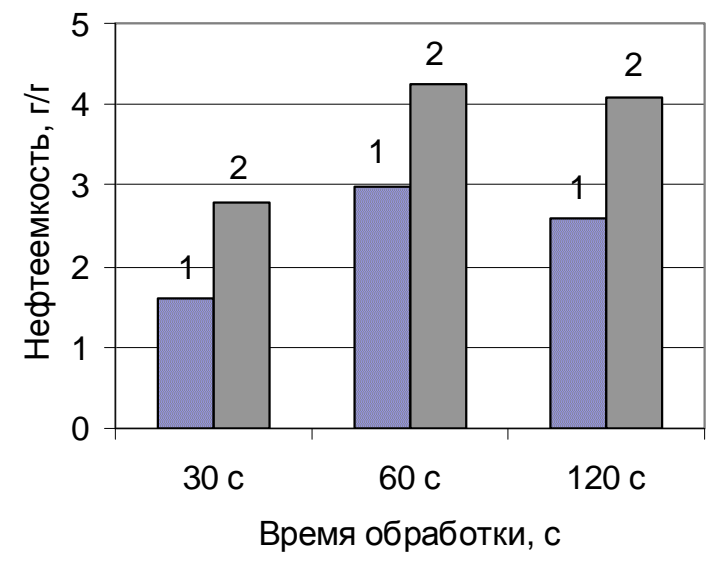

Рис. 2. Влияние продолжительности обработки окорки осины в процессе взрывного автогидролиза на нефтеемкость получаемых сорбентов: $1-170{ }^{\circ} \mathrm{C}$, давление пара $3 \mathrm{MПа;} 2-220^{\circ} \mathrm{C}$, давление пара $3 \mathrm{MПа}$

Таблица 1. Основные факторы и уровни их варьирования

\begin{tabular}{l|c|c|c}
\hline \multicolumn{1}{c|}{ Наименование фактора } & $\mathrm{Z}_{\min }$ & $\mathrm{Z}^{0}$ & $\mathrm{Z}_{\max }$ \\
\hline Температура процесса автогидролиза, ${ }^{\circ} \mathrm{C},\left(\mathrm{Z}_{1}\right)$ & 180 & 210 & 240 \\
Давление пара, МПа, $\left(\mathrm{Z}_{2}\right)$ & 2 & 3 & 4 \\
\hline
\end{tabular}


Переход от натурального масштаба выражения факторов $\left(Z_{1,2}\right)$ к безразмерному осуществляли путем следующих линейных преобразований:

$$
X_{1,2}=\frac{\left(Z_{1,2}-Z_{1,2}^{0}\right)}{\Delta Z_{1,2}},
$$

где $\Delta \mathrm{Z}_{1,2}$ - интервал варьирования независимых факторов.

С целью отыскания коэффициентов математической модели был спланирован полный факторный эксперимент типа $3^{2}$.

Матрица планирования эксперимента и результаты ее экспериментальной реализации приведены в таблице 2.

Таблица 2. Матрица планирования эксперимента

\begin{tabular}{c|c|c|c|c|c}
\hline \multirow{2}{*}{ Номер опыта } & \multicolumn{2}{|c|}{ Факторы в натуральном масштабе } & Факторы в безразмерном масштабе & Отклик (НЕ), г/г \\
\cline { 2 - 6 } & $\mathrm{Z}_{1}$ & $\mathrm{Z}_{2}$ & $\mathrm{X}_{1}$ & $\mathrm{X}_{2}$ & $\mathrm{Y}$ \\
\hline 1 & 180 & 2 & -1 & -1 & 1,5 \\
2 & 180 & 3 & -1 & 0 & 3,0 \\
3 & 180 & 4 & -1 & -1 & 3,6 \\
4 & 210 & 2 & 0 & 0 & 3,2 \\
5 & 210 & 3 & 0 & 1 & 3,8 \\
6 & 210 & 4 & 0 & -1 & 2,9 \\
7 & 240 & 2 & 1 & 0 & 2,5 \\
8 & 240 & 3 & 1 & 1 & 2,5 \\
\hline
\end{tabular}

В результате было получено уравнение регрессии с натуральными обозначениями факторов:

$$
H E=0,357 T+7,9 P-1,233 P^{2}-0,000087 T^{2}-44,944 ; \quad \mathrm{R}=0,93,
$$

где R - коэффициент множественной корреляции.

Оценка значимости коэффициентов уравнения регрессии (2) при уровне значимости q = 0,05 показала, что все коэффициенты значимы.

Качество аппроксимации уравнением (2) оценивали, сравнивая отношение дисперсии относительно среднего $\left(\mathrm{s}_{\mathrm{y}}{ }^{2}\right)$ к остаточной дисперсии $\left(\mathrm{s}_{\text {ост }}{ }^{2}\right)$ и табличное значение критерия Фишера для $\mathrm{q}=0,05 ; \mathrm{f}_{1}=8$ и $\mathrm{f}_{2}=4$ [3]. Так как полученное F-отношение $(7,84)$ больше табличного $(6,04)$, уравнение регрессии считается эффективным.

Задачу поиска оптимальных условий получения сорбента из окорки осины, обеспечивающих его максимальную нефтеемкость, решали методом крутого восхождения по полученной поверхности отклика. Шаг варьирования для температуры составил $5{ }^{\circ} \mathrm{C}$, для давления пара - 0,5 МПа. Для исследованного факторного пространства оптимальные значения факторных признаков в натуральных обозначениях составляют: $\mathrm{T}_{\text {опт }}=$ $205^{\circ} \mathrm{C}, \mathrm{P}_{\text {опт }}=3,0$ МПа. Значение нефтеемкости сорбента из окорки осины $\left(\mathrm{HE}_{\mathrm{P}}\right)$, рассчитанное по уравнению (2) при этих условиях, составляет 4,28 г/г. Был поставлен эксперимент по получению сорбента при оптимальных условиях взрывного автогидролиза. Нефтеемкость (НЕ $)$ этого сорбента составляет 4,30 г/г. Сравнение значений $\mathrm{HE}_{\mathrm{P}}$ и $\mathrm{HE}_{\ni}$ с учетом значения ошибки воспроизводимости $\left(\mathrm{S}_{\text {восп }}=0,04\right.$ г/г) показывает, что уравнение (2) эффективно прогнозирует сорбционную емкость сорбента из окорки осины по нефти.

\section{Bblводbl}

В результате экспериментально-статистического анализа получена двухпараметрическая математическая модель, описывающая получение нефтяного сорбента из окорки осины. Установлено, что математическая модель влияния условий получения сорбента на его сорбционную емкость по нефти эффективно описывает взаимосвязь результативного и факторных признаков. 
На основании двухпараметрической модели были определены оптимальные условия получения нефтяных сорбентов: $\mathrm{T}_{\text {опт }}=205^{\circ} \mathrm{C}$ и $\mathrm{P}_{\text {опт }}=3,0$ МПа. Установлено, что расчетная нефтеемкость сопоставима с величиной нефтеемкости сорбента, полученного взрывным автогидролизом при данных условиях.

\section{Список литературы}

1. Артемов А.В., Пинкин А.В. Сорбционные технологии очистки воды от нефтяных загрязнений // Вода: химия и экология. 2008. №1. С. 19-25.

2. Веприкова Е.В., Терещенко Е.А., Щипко М.Л., Кузнецов Б.Н. Сорбенты для ликвидации нефтяных загрязнений, полученные автогидролизом древесных отходов // Экология и промышленность России. 2011. №3. С. 16-20.

3. Пен Р.З. Статистические методы моделирования и оптимизации процессов целлюлознобумажного производства. Красноярск, 1982. 192 с.

4. Пижурин А.А., Розенблит С.С. Исследования процессов деревообработки. М., 1984. 231 с.

Поступило в редакииюю 18 мая 2012 2.

Veprikova E.V.*,Tereshchenko E.A. OPTIMIZATION OF THE MANUFACTURING PROCESS OF OIL SORBENTS FROM ASPEN BARK WEST

Institute of Chemistry and Chemical Technology SB RAS, Akademgorodok, 50/24, Krasnoyarsk, 660036 (Russia),

e-mail:veprikova2@mail.ru

As a result of experimental and statistical analysis, a two-parameter mathematical model describing the process for the manufacture of a oil sorbent from aspen bark was derived. It has been shown that this model efficiently describes the dependence of the oil capacity of the sorbents on the preparation conditions - the temperature of explosive autohydrolysis processes and pressure of water vapor. Based on the proposed model, optimal conditions for the manufacture of sorbents with maximal oil capacity were determined: $\mathrm{T}_{\mathrm{opt}}=205{ }^{\circ} \mathrm{C}$ and $\mathrm{P}_{\mathrm{opt}}=3,0 \mathrm{MPa}$. It was determined that the calculated oil capacity is comparable with oil capacity value of sorbent producing by explosive autohydrolysis in these conditions.

Keywords: aspen bark, explosive autohydrolysis, sorbent, oil capacity, mathematical model, optimization.

\section{References}

1. Artemov A.V., Pinkin A.V. Voda: khimiia i ekologiia, 2008, no. 1, pp. 19-25. (in Russ.).

2. Veprikova E.V., Tereshchenko E.A., Shchipko M.L., Kuznetsov B.N. Ekologiia i promyshlennost' Rossii, 2011, no. 3, pp. 16-20. (in Russ.).

3. Pen R.Z. Statisticheskie metody modelirovaniia $i$ optimizatsii protsessov tselliuloznobumazhnogo proizvodstva. [Statistical modeling and optimization of pulp and paper production]. Krasnoyarsk, 1982, 192 p. (in Russ.).

4. Pizhurin A.A., Rozenblit S.S. Issledovaniia protsessov derevoobrabotki. [Research processes woodworking]. Moscow, 1984, 231 p. (in Russ.).

Received May 18, 2012

\footnotetext{
"Corresponding author.
} 